\title{
Case based psychosocial exploration of flirting
}

\author{
Manoj Kumar Sharma* \\ Clinical Psychology, SHUT clinic (Service for Healthy use of Technology), National Institute of Mental health \& Neurosciences, Bengaluru, Karnataka, India
}

\section{Introduction}

Flirting has become a modality for initiating courtship or quasicourtship .Flirting can happen verballyas well as non-verbally.The use of touch and frequent indulgence in clothing adjustment are other common form of flirtatious behaviour. The other expression of flirting includes the amount of personal distance kept between individuals.It has been seen that male \& female who leans toward each other or who are at the same body angle found to be more seductive.

Flirting is more frequent among younger people in the age group of 18-24 years. The Flirting Report Social Issues Research Centre (2004) [1] in their national survey found that males were slightly more flirtatious than females, with more men admitting to 7 recent flirtations than women. 61 percent acknowledged of having flirted either today or within the past week. The flirting behaviours can happen among individuals who got personality disorders. The person with a histrionic personality disorder also has the characteristic of being flirtatious, seductive, charming, manipulative, impulsive, and lively. They may behave inappropriately with most of the people they meet, even when they are not sexually attracted to them $[2,3]$.

It is not a well-researched area. The present case sought consultation for management of his flirting behaviours.

\section{Case}

Mr SP, a 24 years old graduate, employed, from middle economic status family presented with complaints of increased preference for interaction with opposite sex. He got warning for his glancing behaviors which has increased for the last 4 years. This behavior was observed when he was 15 years old. The observations included focusing more on grooming to look impressive, giving smile or tendency to interact with opposite sex or initiating communication in the form of asking their personal details, interests/preferences, status, othersused to become uncomfortable whenever he minimizes the space with them. It used to happen even in the first meeting with others. He reported increased indulgence in masturbatory practices as well as fantasizing about opposite sex. There is increase interest in accessing videos for enhancing self-presentation as well as impressing others. He enjoyed indulgence in these behaviors and interacting with opposite sex or building friendship with them. He was found to be mixed personality (Histrionic, Schizotypal, Narcissistic) on the Structured Clinical Interview for Personality Disorders. He was maintaining well in other domains of psychosocial functioning. He did not have lifetime /current history of any other clinical psychiatric disorder. He was receptive to psychotherapy work on minimizing the consequences of his current problems as well as reducing the indulgence in these behaviors.

\section{Discussion and conclusions}

The current case highlights the presence of ego syntonic flirting behaviors for treatment consultation. The case also meets the first three stages of five stage model of courting [4]. Though it was proposed for women, these stages have implications in terms of understanding flirting behavior. These stages use nonverbal gestures to initiate flirting. It included attention stage where individual use quickglance at and away from people and second stage of recognition phase includeduse smiling, eyebrow flashes to impress other and third stage included initiating conversation with other.

The people flirt for a variety of reasons including the desire to increase sexual interaction. The motivational needs associated with flirting are sex (wants to have a physical intimacy); fun (as one of activity to feel good); exploring (modality to experience this behavior); relational (enhance intimacy in interaction or relationship); esteem (to enhance one's self-image) and instrumental (goal of getting something out of the relationship) [5]. The present study also had corroboration from error management theory which showed that men tend to over perceive sexual interest from women, while women tend to under perceive sexual interest from men [6]. It also explained the highest percentage of male engaged in this kind of behaviours.

The flirting is strongly related to personality traits such as extroversion, openness and negatively related to conscientiousness, reflecting the outgoing nature but with a lack of concern for otherStudies also have shown that people with histrionic personalityoften involve themselves in flirtatious behaviour such as drawing attention to oneself by wearing bright coloured clothing or revealing garments [7]. They tend to be extremely emotionally expressive [8]. These things got increased expression through online modality.

New media technologies have changed the ways young people interact with one another, and many are learning how to negotiate their romantic and sexual relationships within these new contexts. The Internet makes it feasible for individual with histrionic personality traits to make more connections with persons. It was seen that participants viewed online mode of communication as something that facilitates planning social activities, maintaining ties with friends, and feeling part of a community [9].

Flirting behaviour can manifest both offline and online. There is a greater need to look into these behaviours in the background of personality and technological influence. This case study helps in exploring flirting behaviour, sexual identity, relationship-building (offline and online) in the background of personality, forproviding insight to the development of individualized intervention program.

${ }^{\star}$ Correspondence to: Manoj Kumar Sharma, Clinical Psychology, SHUT clinic (Service for Healthy use of Technology), National Institute of Mental health \& Neurosciences, Bengaluru, Karnataka, India, E-mail: shutclinic@gmail.com

Received: September 24, 2020; Accepted: October 09, 2020; Published: October 12,2020 


\section{References}

1. The flirting report (2004) The social issues Research centre.

2. Lilienfeld SO, Van Valkenburg C, Larntz K, Akiskal HS (1986) The relationship of histrionic personality disorder to antisocial personality and somatization disorders. $\mathrm{Am}$ J Psychiatry 143: 718-722. [Crossref]

3. French JH, Shrestha S (2019) Histrionic Personality Disorder. In StatPearls Publishing.

4. Givens D (1978) The nonverbal basis of attraction: Flirtation, courtship, and seduction. Psychiatry 41: 346-359. [Crossref]

5. Henningsen DD (2004) Flirting with meaning: An examination of miscommunication in flirting interactions. Sex roles 50: 481-489.
6. Haselton MG, Buss DM (2000) Error management theory: A new perspective on biases in crosssex mind reading. J Pers Soc Psychol 78: 81-91. [Crossref]

7. Hall JA, Carter S, Cody MJ, Albright JM (2010) Individual differences in the communication of romantic interest: Development of the flirting styles inventory. Communication Quarterly 58: 365-393.

8. Rienzi BM, Scrams DJ (1991) Gender stereotypes for paranoid, antisocial, compulsive, dependent, and histrionic personality disorders. Psychol Rep 69: 976978. [Crossref]

9. McMillan SJ, Morrison M (2006) Coming of age with the internet: A qualitative exploration of how the internet has become an integral part of young people's lives. 8: 73-95.

Copyright: (C2020 Sharma MK. This is an open-access article distributed under the terms of the Creative Commons Attribution License, which permits unrestricted use, distribution, and reproduction in any medium, provided the original author and source are credited. 